\title{
Severe Combined Immunodeficiency with Selective T-Cell Cytokine Genes
}

\author{
EMANUELA CASTIGLI, RAIF S. GEHA, AND TALAL CHATILA \\ Division of Immunology, Children's Hospital, and the Department of Pediatrics, Harvard Medical School, \\ Boston, Massachusetts 02115
}

\begin{abstract}
A 4-y-old female with severe combined immunodeficiency disease had normal numbers of $\mathbf{T}$ cells in her circulation and normal T-cell subsets. However, her T cells proliferated poorly to mitogens and did not proliferate to antigens or to anti-CD3 MAb. IL-2 receptor expression was normal, but IL-2 synthesis was undetectable. The addition of recombinant IL-2 to a mitogen-stimulated culture resulted in normalization of the proliferative response. Northern blot analysis of total RNA derived from the patient's $T$ cells revealed a weak or absent expression of mRNA coding for IL-2, IL-3, IL-4, and IL-5. In contrast, there were normal amounts of mRNA coding for granulocyte-macrophage colony-stimulating factor. Tumor necrosis factor and IL-6 production were also normal. Nuclear run-on transcriptional assays revealed markedly decreased levels of newly initiated nuclear transcripts coding for IL2, IL-3, IL-4, and IL-5 and normal levels of granulocytemacrophage colony-stimulating factor transcripts in the patient relative to control lymphocytes. Gel retardation assays suggest that the NFAT-1 nuclear transcription complex is abnormal in this patient. These results indicate that the patient suffers from a defect that affects the transcription of multiple T-cell lymphokines and suggest that abnormalities affecting the production of T-cell lymphokines may underlie some of the primary immunodeficiency diseases. (Pediatr Res 33 (Suppl): S20-S23, 1993)
\end{abstract}

\section{Abbreviations}

IFN- $\gamma$, interferon- $\gamma$

NFAT, nuclear factor of activated $T$ cells

TCR, T-cell receptor

TNF, tumor necrosis factor

Cellular and humoral immune responses to antigens are strictly dependent on the synthesis by activated T cells of a multitude of soluble factors. These factors include the IL, IFN- $\gamma$, colony stimulating factors, TNF- $\alpha$ and TNF- $\beta$, transforming growth factor- $\beta$, and other as yet uncharacterized factors $(1,2)$.

We describe a case of primary severe combined immunodeficiency disease with normal numbers and phenotypes of circulating lymphocytes that were deficient in their capacity to synthesize multiple lymphokines.

\section{CASE REPORT}

The patient, who is a girl, is 4 y 8 mo old and was born at 37 wk of gestation. At 2 mo of age, the patient developed a generalized vesicular eruption after exposure to a sibling with chicken

Correspondence: Raif S. Geha, M.D., Children's Hospital, Enders Building, 8th Floor, 300 Longwood Ave., Boston, MA 02115-5757. pox. This ultimately resolved after i.v. therapy with acyclovir. Investigation of her immune function at $6 \mathrm{mo}$ of age revealed normal lymphocyte count and phenotype, an absent delayedtype hypersensitivity response to a battery of seven antigens, impaired in vitro proliferation of $\mathrm{T}$ cells to mitogens, hypogammaglobulinemia (IgG $170 \mathrm{mg} / \mathrm{mL} ; \mathrm{IgA}<1 \mathrm{mg} / \mathrm{mL} ; \mathrm{IgM} 12 \mathrm{mg} /$ $\mathrm{mL}$ ) and low varicella zoster titers (IgG 1:16; IgM 1:8). Tests for human immunodeficiency virus in the child and in the mother were negative. Tests for the activity of adenosine deaminase and purine nucleoside phosphorylase were normal. The patient was placed on i.v. immune globulin, yet she suffered from progressive opportunistic infections including oral thrush and Pneumocystis carinii pneumonia and failed to thrive. At 6 and 8 mo of age, she received two bone marrow transplants with a T-cell-depleted haploidentical (paternal) bone marrow graft. Based on the observation that the patient's $T$ cells failed to secrete detectable amounts of IL-2 upon stimulation with mitogens but proliferated well to the combination of mitogens and exogenous IL-2, the patient was started on i.v. IL-2 replacement therapy with a remarkable clinical response (3).

\section{RESULTS}

Flow cytometric analysis of the patient's circulating lymphocytes at the age of 6 mo revealed normal absolute numbers and percentages of $\mathrm{T}$ cells that expressed the TCR/CD3 complex, CD4, and CD8. Despite their normal number and phenotype, the patient's lymphocytes failed to proliferate in response to the mitogenic anti-CD3 MAb OKT3 (Ortho Pharmaceutical Corp., Raritan, NJ) to a mitogenic combination of anti-CD2 MAb, OKT $11+9.6$, or to phytohemagglutinin (Table 1). Most importantly, as shown in Table 1, the proliferative defect was corrected by the addition of recombinant IL-2. Table 2 demonstrates that mitogens induced the expression of the IL-2 receptor on the patient's $T$ cells, albeit to a lesser extent than that observed for control T cells. However, the secretion of IL-2 by the patient's T cells upon their activation by agonistic antibodies was either severely defective or undetectable. This defective cytokine production was restricted to T cells and involved IFN- $\gamma$ as well as IL-2. In contrast, the monocyte-derived cytokines, (IL-4, TNF$\alpha$, and IL-6) were produced normally (Table 3 ).

The defective synthesis of multiple lymphokines by the patient's $T$ cells could be the result of an abnormality affecting the transduction via cell surface receptors of signals necessary for the induction of lymphokine synthesis, e.g. elevation in free intracellular $\mathrm{Ca}^{2+}$, and activation of protein kinase $C$ (4). Alternatively, the defective production of lymphokines by the patient's lymphocytes could have resulted from a more distal abnormality. Treatment of the patient's peripheral blood lymphocytes with the protein kinase $\mathrm{C}$ activator phorbol myristate acetate and the calcium ionophore ionomycin could induce only a modest synthesis of IL-2, IFN- $\gamma$, and IL-4. This suggested that the defective synthesis of lymphokines by the patient's peripheral blood T cells was related to an abnormality distal to the generation of 
Table 1. Immunologic function of patient and control $T$ lymphocytes*

\begin{tabular}{|c|c|c|}
\hline \multirow[b]{2}{*}{ Stimulus } & \multicolumn{2}{|c|}{$\begin{array}{c}\left({ }^{3} \mathrm{H}\right) \text { Thymidine incorpo- } \\
\text { ration }(\mathrm{cpm})\end{array}$} \\
\hline & Patient & Control \\
\hline Medium & 538 & 1911 \\
\hline Medium + IL-2 & 13336 & 60060 \\
\hline Anti-CD3 (OKT3) & 720 & 22680 \\
\hline Anti-CD3 + IL-2 & 67785 & 198090 \\
\hline Anti-CD2 & 673 & 183487 \\
\hline Anti-CD2 + IL-2 & 298610 & 268160 \\
\hline PHA-P & 25583 & 365690 \\
\hline PHA + IL-2 & 521010 & 418070 \\
\hline
\end{tabular}

* Recombinant IL-2 was used at $100 \mathrm{U} / \mathrm{mL}$. All MAb were used at 1 $\mu \mathrm{g} / \mathrm{mL}$ and PHA-P was used at $10 \mu \mathrm{g} / \mathrm{mL}$. Results are means of triplicate determinations. Similar results were found in five other experiments. PHA, phytohemagglutinin.

Table 2. IL-2 and IL-2 receptor $(I L-2 R)-\alpha$ chain expression*

\begin{tabular}{lccccc}
\hline \multirow{2}{*}{\multicolumn{1}{c}{ Stimulus }} & \multicolumn{2}{c}{$\mathrm{IL}-2 \mathrm{R}(\%+$ cells $)$} & & \multicolumn{2}{c}{$\mathrm{IL}-2(\mathrm{fmol} / \mathrm{mL})$} \\
\cline { 2 - 3 } \cline { 5 - 6 } & Patient & Control & & Patient & Control \\
\hline Medium & $<2$ & $<2$ & & ND & ND \\
PHA & 20 & 69 & & 1.5 & 947 \\
PMA + ionomycin & 30 & 75 & & 69 & 3262 \\
\hline
\end{tabular}

* IL-2R expression was assessed by fluorescence-activated cell sorter analysis $48-72 \mathrm{~h}$ after stimulation. IL-2 was assessed by an RIA in supernatants of $1 \times 10^{6}$ cells using an anti-IL-2R- $\alpha$ chain MAb conjugated to FITC. PHA, phytohemagglutinin; PMA, phorbol myristate acetate.

Table 3. Cytokine synthesis after PMA plus ionomycin stimulation*

\begin{tabular}{lcc}
\hline & Patient & Control \\
\hline IL-2 (fmol/mL) & 69 & 2745 \\
IFN- $\gamma($ units/mL) & 75 & 782 \\
IL-4 $(\mathrm{pg} / \mathrm{mL})$ & 3 & 110 \\
IL-6 $(\mathrm{ng} / \mathrm{mL})$ & 29 & 30 \\
TNF- $\alpha(\mathrm{pg} / \mathrm{mL})$ & 400 & 370 \\
\hline
\end{tabular}

* PMA (phorbol myristate acetate) was used at $20 \mathrm{ng} / \mathrm{mL}$ and ionomycin at $0.5 \mu \mathrm{M}$. Similar results were found in three other experiments.

second messengers that follows the engagement of the TCR/CD3 complex (5).

T-cell lines were generated from the patient's peripheral lymphocytes and were similar to the patient's peripheral blood T cells in their inability to secrete lymphokines upon stimulation with mitogens. Northern blot analysis of total cellular RNA isolated from these cell lines upon activation with phorbol myristate acetate and ionomycin revealed profound decreases in the levels of mRNA coding for IL-2, IL-3, IL-4, IL-5, and IFN- $\gamma$ with otherwise normal message size for each of these lymphokines (6) (Fig. 1). The time courses for lymphokine mRNA accumulation in patient and in control lymphocytes were identical. The specificity of these abnormalities was suggested by normal mRNA levels found for two other genes transcribed by $T$ cells, the cytokine granulocyte-macrophage colony-stimulating factor (Fig. 1) and the TCR-associated protein CD3- $\zeta$.

The decreased lymphokine mRNA levels could result from a decreased rate of initiation of lymphokine gene transcription upon lymphocyte activation. Alternatively, it could result from enhanced degradation of lymphokine mRNA, which is otherwise transcribed at a normal rate. To differentiate between these two possibilities, we used a nuclear run-on transcription assay. The results obtained showed that the rate of initiation of IL-2, IL-4, and IL-5 transcription upon cell activation was markedly de-
Control

Patient

$03622^{*}$

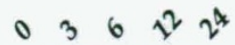

IL-2

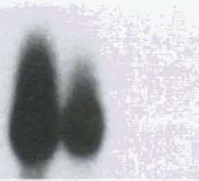

IL-3

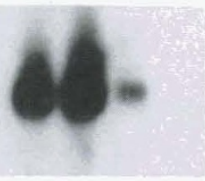

IL-4

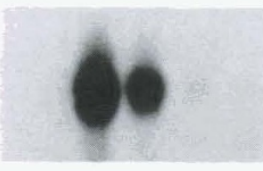

IL-5

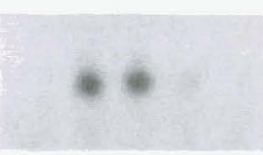

Interferon- $\gamma$

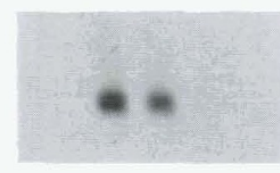

GM CSF
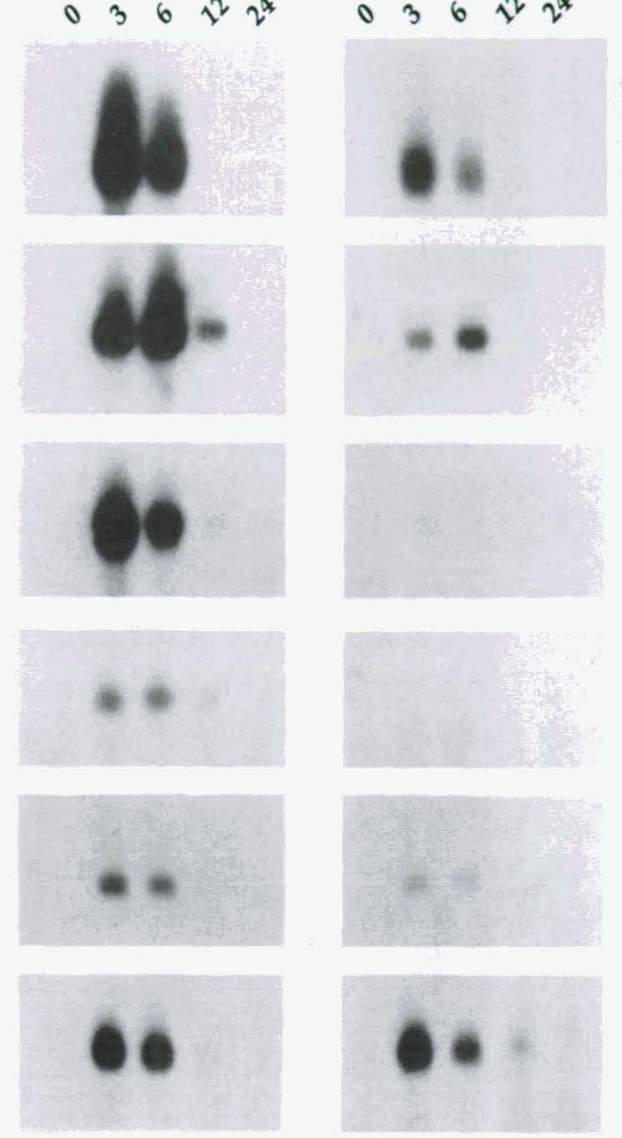

RNA
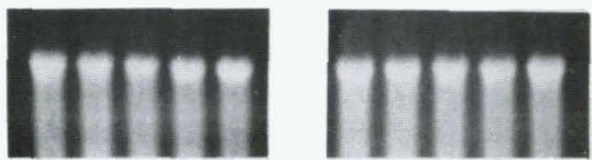

Fig. 1. Expression of lymphokine mRNA in patient and in control T-cell lines stimulated with phorbol myristate acetate at $20 \mathrm{ng} / \mathrm{mL}$ and $0.5 \mathrm{mM}$ ionomycin for the indicated periods (in h). Ten $\mu \mathrm{g}$ of total cellular RNA per sample were fractionated on $1 \%$ agarose/formaldehyde gel, transferred to nitrocellulose filters, and probed for the respective lymphokine, as described. GM-CSF, granulocyte-macrophage colonystimulating factor.

creased in the patient's T cells as compared to control lymphocytes (6) (Fig. 2). Thus, the defect in the patient's lymphocytes involved a failure of initiation of lymphokine gene transcription. The defect in the patient's lymphocytes likely involves an abnormality affecting a regulatory factor that participates in the initiation of transcription of these lymphokines upon T-cell activation.

Several DNA regulatory elements govern the transcription of IL-2. These include NF- $\kappa$ B, AP-1, OCT-1, and NFAT-1 (Fig. 3). The migration of NFAT-1 complex was faster in the patient than in controls. In contrast, migration patterns of NF- $\mathrm{kB}, \mathrm{AP}-1$, and OCT-1 complexes were normal. The results suggest that the patient's defect involved a defective NFAT-1-binding complex. We are currently assessing the functional significance of this abnormality by examining the capacity of NFAT-1 oligonucleotide versus AP-1, NF- $\kappa$ B, and OCT-1 oligonucleotides to drive the transcription of a reporter gene in T-cell lines derived from the patient versus controls.

The causal relationship between defective IL-2 production by the patient's lymphocytes and her immunodeficiency state was highlighted by the complete correction of the poor in vitro proliferative responses of her lymphocytes to mitogens and the 


\section{Control}

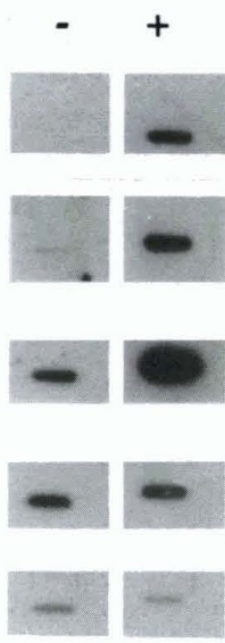

\section{Patient}

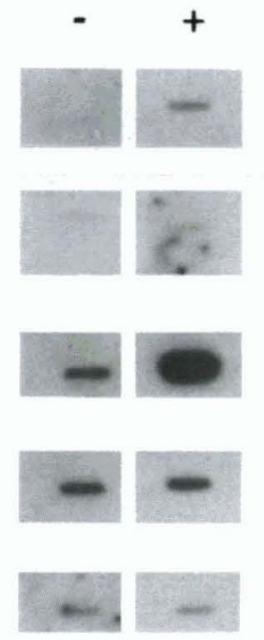

IL-5

\section{GM-CSF}

\section{Actin}

\section{PBR 322}

Fig. 2. Assay for initiation of transcription of lymphokine genes in patient and control T-cell lines either left untreated (-) or stimulated with phorbol myristate acetate and ionomycin for $1 \mathrm{~h}(+)$. Nuclear RNA was prepared, labeled, and, after equalization for number of counts in patient and control samples, probed for respective lymphokine transcripts, as described. Transcripts of noninducible $\beta$-actin gene were used as positive control, and plasmid pBR322 DNA (PBR 322) was used to measure nonspecific hybridization. $G M-C S F$, granulocyte-macrophage colony-stimulating factor.

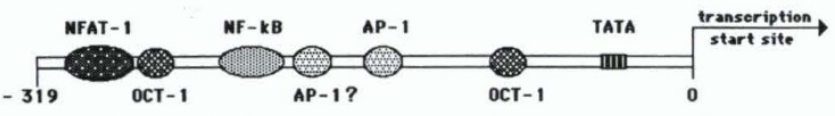

Fig. 3. Protein-binding sites on the regulatory region of IL-2.

improvement in her clinical status upon initiation of IL-2 replacement therapy (3). Interestingly, despite defective expression of multiple lymphokines, replacement therapy with IL-2 alone was sufficient to restore her immune function. IL-2 could upregulate the production of some lymphokines that are defectively expressed by the patient's lymphocytes, e.g. IFN- $\gamma$. Indeed IL-2 supplementation caused a modest increase in IFN- $\gamma$ production by the patient's lymphocytes (data not shown). The function of other lymphokines such as IL-3 is to a large extent redundant because of its similarity to that of cytokines such as colonystimulating factors (e.g. granulocyte-macrophage colony-stimulating factor), the production of which was apparently unaffected. This would account for the normal hematopoiesis observed in this patient.

\section{REFERENCES}

1. Dinarello CA, Mier JW 1987 Lymphokines. N Engl J Med 317:940-945

2. Kronke M, Leonard WJ, Depper JM, Greene WC 1985 Sequential expression of genes involved in human $\mathrm{T}$ lymphocyte growth and differentiation. $\mathrm{J}$ Exp Med 161:1593-1598

3. Pahwa R, Chatila T, Pahwa S, Paradise C, Day NK, Geha RS, Schwartz SA, Slade H, Oyaizu N, Good RA 1989 Recombinant interleukin 2 therapy in severe combined immunodeficiency disease. Proc Natl Acad Sci USA $86: 5069-5073$

4. Chatila TA, Wong R, Young M, Miller R, Terhorst C, Geha RS 1989 An immunodeficiency characterized by defective signal transduction in $\mathrm{T}$ lymphocytes. N Engl J Med 320:696-702

5. Weiss A, Imboden J, Hardy K, Manger B, Terhorst C, Stobo J 1986 The role of the T3/antigen receptor complex in T-cell activation. Annu Rev Immunol 4:593-619

6. Chatila TA, Castigli E, Pahwa R, Good R, Geha RS 1990 Primary combined immunodeficiency resulting from defective transcription of multiple T-cell lymphokine genes. Proc Natl Acad Sci USA 87:10033-10037

\section{FLOOR DISCUSSION}

Dr. Ballow: Are antibodies to NFAT available?

Dr. Geha: No, they are not. NFAT is a little complex. It has

more than two components. Two components are currently being cloned by Dr. Gerry Crabtree. There is a third component of NFAT that was just described by a group at the NIH (National Institutes of Health).

Dr. Ballow: Do you mean chain?

Dr. Geha: Yes, and as we were doing the study, something interesting came up. There is competition between the AP-1 sequence and the NFAT sequence for binding to NFAT. Furthermore, the AP-1 jun/fos dimers bind to NFAT-1 and can form part of the NFAT complex. This may be important in the way the amount of IL-2-driven expression is regulated, because there is a lot of AP-1 around. Very little is known about the structure of NFAT, but in addition to the nuclear and cytoplasmic components, which are in the $40-$ to $50-\mathrm{kD}$ range, there is an additional component with a lower molecular mass of about $27 \mathrm{kD}$. From our gel retardation data, this patient shows a fast-migrating NFAT-1 complex, which suggests that a component of the complex is defective.

Dr. Gelfand: Are you suggesting that this patient has both the cytoplasmic and the nuclear, but the association is abnormal?

Dr. Geha: Yes. If you look at $2 \mathrm{~h}$, this patient's NFAT complex migrates identically to normal NFAT, but when you look at 4 and $8 \mathrm{~h}$, the pattern changes. When we exchanged reagents with Dr. Crabtree, the position at which our patient's NFAT migrates at 4 and $8 \mathrm{~h}$ is the same abnormal position as his reconstituted nuclear plus cytoplasmic component. Thus, a third component of NFAT may be abnormal or unstable.

Dr. Gelfand: I understand. So why couldn't the defect be at the level of the phosphatase that is responsible for the nuclear translocation?

Dr. Geha: In our study, we have taken the nuclear extract, so the cytoplasmic component, the putative target of the phosphatase, is already translocated to the nucleus.

Dr. Gelfand: But they fall off?

Dr. Geha: That is true. So either there is a component that is falling off or maybe one of the two chains is unstable and breaks down.

Dr. Gelfand: But the phosphate may be insufficient and limiting?

Dr. Geha: Perhaps, but at $2 \mathrm{~h}$ the intensity of the NFAT complex in the nuclear extract is not bad at all. It is the position that falls off later.

Dr. Gelfand: In the cyclosporine effects, once you activate the cells to promote the initial regulation or transcription of IL-2, cyclosporine is no longer able to inhibit the subsequent transcription. In a way, your case resembles this situation in that you have initial transcription.

Dr. Geha: No. Phenotypically it looks like a cylcosporine defect but it is indeed a different defect. Phenotypically it looks as if this patient has been taking cyclosporine so the NFAT-1 isn't working.

Dr. Gelfand: Have you tried to stimulate IL-2 transcription through the other cyclosporine so-called resistant pathway by taking PMA (phorbol myristate acetate) and anti-CD28 to determine whether or not NFAT is turned on appropriately or IL-2 is turned on?

Dr. Geha: No, we have not. But since in transfection assays the CD28 effect on IL-2 transcription depends on an intact NFAT element (but not vice versa) it is unlikely that anti-CD28 will correct the defect. Note added in revision: No correction was obtained when anti-CD28 was tested.

Dr. Strober: In my talk this morning, I mentioned that among the common variable immunodeficiency patients, those that made less IL-2 than normal had considerable reconstitution of their cells when they were stimulated with anti-CD28. AntiCD28 apparently uses a different nuclear transcription factor and different site, $5^{\prime}$ to the IL-2 gene. So one would predict that anti-CD28 will give you a much more normal pattern in this case as well. It is worth trying.

Dr. Sorensen: Do you know if all the patients who have IL-2 
deficiency and severe combined immune deficiency have a similar defect? I ask you the question because Mel Berger and I have been following a child with no IL-2 expression who clearly does not have severe combined immune deficiency and who seems to have a restricted and very severe defect of proliferation. That child is now 15 y old. We were quite puzzled as to why this patient of ours appears to be doing relatively well, save when he gets unusual infections, and why patients like the one you described develop severe combined immune deficiency. I think you have given us a clue there, but I wonder if this is a general problem.

Dr. Geha: We have only found one patient. As you know, Robbie Parkman had another patient who looked different. Richard O'Reilly also had a patient with IL-2 deficiency, but I don't remember all the data on that case.

Dr. Gelfand: That is important because the patient described in the Flominberg paper also had IL-4 and some normal IFN- $\gamma$. If I look at the gels very carefully, it seems to me it wasn't only IL-2 but other genes that were down and only IFN- $\gamma$ was expressed normally. So this may be a common phenotype. I'm not sure we've seen a true IL-2 gene deletion described in the literature yet.

Dr. Geha: I agree with you.

Dr. Gelfand: Why do you think this patient is hypogammaglobulinemic?

Dr. Geha: I think if your T cells are not doing too well, your B cells won't do too well.

Dr. Gelfand: That makes sense to me. The gene knockout experiments with these individual lymphokines have shown that the immunoglobulins are not going down except for $\operatorname{IgE}$ and the IL-4 type and so on. It is an interesting association.

Dr. Geha: Actually our patient's B cells were tested, and they were in what we consider a stressful system, an IgE production system, and did very well.

Dr. Pahwa: As in the case you described, we did a bone marrow transplantation in one of our patients, using busulfan (at $16 \mathrm{mg} /$ $\mathrm{kg}$ ) and cyclophosphamide (at $200 \mathrm{mg} / \mathrm{kg}$ ), and she rejected the marrow. We did a second transplant and she rejected the second transplant. In severe combined immune deficiency, if there is no matched sibling and repeated rejection of the marrow, I think one should consider the possibility of some cytokine deficiency. Patients with IL-2 deficiency are more difficult to reconstitute and, as we have heard at this meeting, ADA-deficient (adenosine deaminase-deficient) patients are difficult to reconstitute. In some of these subgroups, I think we should look for patients who have not been reconstituted and have one of the cytokine deficiencies.

Dr. Geha: We would like to study your patient if you are willing to share some cells.

Dr. Gelfand: Dr. Pahwa, I am not quite sure I understand which cytokine-deficient patients you feel are harder to engraft, because every SCID (patient with severe combined immune deficiency) is cytokine deficient if they don't have T cells, as most SCIDs don't.

Dr. Pahwa: When you do a bone marrow transplantation using cyclophosphamide, busulfan, or any cytoreduction, there is a temporary reconstitution of the donor T cells. The donor T cells will produce IL-2, and that IL-2 immediately will induce a rejection. So in these patients you have to go for a higher cytoreduction, which is $24 \mathrm{mg}$ of busulfan and $240 \mathrm{mg}$ of cyclophosphamide. If you give a little less, you get a temporary engraftment, but as soon as you get donor-derived IL-2 there is immediate rejection. That is a problem we have observed with IL-2 deficiency: when we transplant we get rejection. I believe this is also the observation from Duke University. Am I correct, Dr. Schiffer?

Dr. Schiffer: That is correct. 